DOI: https://doi.org/10.46296/yc.v4i7edesp.0081

\title{
IMPACTO DE LA MIGRACIÓN RURAL A LA CIUDAD EN EL CANTÓN CHONE, ECUADOR
}

\section{IMPACT OF RURAL-URBAN MIGRATION IN THE CHONE CANTON, ECUADOR}

\author{
Zambrano-Vera María Roxana ${ }^{1 *}$; Hidalgo-Ávila Argelio Antonio² \\ ${ }^{1}$ Maestrante en Administración de Empresas, mención: Gerencia de calidad y productividad, \\ Pontificia Universidad Católica del Ecuador - sede Manabí, PUCESM. Portoviejo, Ecuador. \\ Orcid: https://orcid.org/0000-0001-7528-7171
}

${ }^{2}$ Pontificia Universidad Católica del Ecuador - Sede Manabí, PUCESM. Portoviejo, Ecuador.

Orcid: https://orcid.org/0000-0002-1952-5312

*Correo: mzambrano7819@pucem.edu.ec

\begin{abstract}
Resumen
El presente artículo tiene como objetivo identificar el impacto provocado por la migración rural al cantón Chone, para esto se empleó una revisión bibliográfica del año 2000 hasta la actualidad, de publicaciones científicas y estadísticas de páginas y organismos certificados. Los movimientos de población tanto al interior como por fuera de un país, constituyen una de las cuestiones que más atención ha recibido en los últimos tiempos, buscando las causas que generan estos movimientos poblacionales y conocer los impactos que provocan. En América Latina, la migración obedeció a importantes diferencias entre los niveles de ingreso per cápita de los países, en especial de los limítrofes. A principios del siglo XX. Ecuador se convirtió en el primer país de la Región Andina de emigración hacia Europa y Estados Unidos. A medida que los países van transitando de sociedades predominantemente rurales a sociedades cada vez más urbanas, se va incrementando la migración rural-urbana, provocando que la migración interna supere ampliamente la migración internacional. Esta migración interna en el cantón Chone tiene efectos directos en los procesos de urbanización y se han visto influidos por la mecanización de la agricultura, la concentración y acumulación de la propiedad rural y el escaso dinamismo del sector agrícola tradicional. La mayoría de la población se concentra en zonas donde existe disponibilidad de servicios básicos, infraestructura, educación y salud; de preferencia con cercanía o con buena accesibilidad.
\end{abstract}

Palabras clave: Migración, rural, urbana, impacto, Chone.

\begin{abstract}
The objective of this article is to identify the impact caused by rural migration to the Chone canton. For this purpose, a bibliographic review from 2000 to the present, of scientific publications and statistics of pages and certified organizations, was used. Population movements both inside and outside a country constitute one of the issues that has received the most attention in recent times, seeking the causes that these population movements generate and knowing the impacts they cause. In Latin America, migration was due to important differentials between the levels of per capita income of the countries, especially bordering ones. At the beginning of the 20th century, Ecuador became the first country in the Andean Region to emigrate to Europe and the United States. As countries move from predominantly rural societies to increasingly urban ones, urban rural migration increases, causing internal migration to far outweigh international migration. This internal migration in the Chone ridge has direct effects on urbanization processes and has been influenced by the mechanization of agriculture, the concentration and accumulation of rural property and the low dynamism of the traditional agricultural sector. Most of the population is
\end{abstract}

Información del manuscrito:

Fecha de recepción: 01 de agosto de 2020

Fecha de aceptación: 21 de agosto de 2020

Fecha de publicación: 16 de noviembre de 2020 
concentrated in areas where there is availability of basic services, education and health infrastructure; preferably with proximity or with good accessibility.

Keywords: Migration, rural, urban, impact, Chone.

\section{Introducción}

La movilidad humana es un fenómeno registrado desde el inicio de la historia, las causas son muchas y van desde mejores condiciones geográficas hasta la búsqueda de oportunidades.

Durante toda la historia de la humanidad se registran movimientos masivos de poblaciones a lo largo del mundo, los principales motivos fueron escasez de alimentos, guerras, inundaciones, sequías, esclavitud, libertad económica, explotación y negocios. Petit (2002) en su publicación "Migraciones, vulnerabilidad y políticas públicas" profundiza en las causas de la migración y sus consecuencias.

La migración según Eguiguren (2017) se registra en todas las esferas sociales, de manera internacional, nacional e incluso a nivel de la estructura política de las provincias y cantones.

Las tendencias migratorias en América del Sur guardan relación con las tendencias históricas que se han desarrollado en América Latina y el Caribe. Esto quiere decir que los ya clásicos patrones de emigración extra-regional, inmigración histórica de ultramar y los intercambios intrarregionales, continúan sintetizando los distintos movimientos de personas que se producen en la subregión desde el siglo XX en adelante. Sin embargo, el dinamismo actual de los movimientos migratorios define ciertas tendencias particulares al interior de los tradicionales patrones de movimiento que requieren ser visibilizados. En términos generales, la ronda de censos de 2010 confirma por una parte, algunas tendencias que se venían gestando desde hace algún tiempo en América Latina y el Caribe y evidencia por otra, algunas especificidades producto de los contextos políticos globales que se han suscitado en el último tiempo y situaciones específicas que ocurren a nivel regional. En términos de tendencias generales se confirma una disminución reciente de los flujos de emigración dirigidos a los tradicionales países extrarregionales (Estados Unidos, Canadá y España); 
una pérdida de importancia relativa y absoluta de la inmigración proveniente de otras regiones, un crecimiento y mayor dinamismo en la migración intrarregional y la constatación de que la región continúa siendo, en el balance global, un lugar de emigración más que de inmigración (CEPAL, 2018).

En Ecuador existe la Comisión Especial de Estadística de Población y Migración que tiene como objetivo: "Impulsar la producción y fortalecimiento de la información sobre población y migración a través del diseño, desarrollo e implementación de planes y proyectos en materia estadística en garantía de cumplimiento de la agenda nacional para desarrollo, las agendas sectoriales y territoriales, y planes de desarrollo internacionales" (INEC, 2019).

No obstante, el desplazamiento humano genera cambios profundos en la sociedad, muchos de ellos traen consigo el abandono de ciudades que alguna vez fueron productivas, separación de la familia, desaceleración de la economía en la ciudad de la cual se emigra. Walmsley (2001) en su investigación "Transformando los pueblos: La migración Internacional y el Impacto social al nivel comunitario" demuestra el impacto de la migración en las comunidades del Ecuador.

Las migraciones se producían inicialmente por regiones, posteriormente entre países e incluso a otros continentes, sin embargo, estos fenómenos migratorios no solo se presentan a escala internacional o nacional, dentro de la estructura social de cada cantón se identifican zonas por características naturales, sean estos de la costa, sierra u oriente, en cada cantón por ejemplo tenemos identificado plenamente la zona rural y la urbana, entendiendo que la primera representa al sector de la campiña y la segunda el área citadina o ciudad. El cantón Chone ha registrado fuertes movimientos migratorios de la zona rural a la urbana, generando muchas veces situaciones adversas o favorables dependiendo del sector de la sociedad en la que se enfoque.

La escasez de trabajo en la ciudad, sumada a la cantidad de personas que optan por migrar, engrosan las cifras de desempleo, en este punto Villarroya (2014) define a la 
migración como el "Derecho que se fundamenta en ofrecer posibilidades de supervivencia y mejora a todos los seres humanos" pero, ¿Qué sucede cuando el lugar al que se emigra no da las oportunidades laborales esperadas?, partiendo del hecho que es una oportunidad de supervivencia.

El objetivo de la presente investigación es determinar el impacto que genera la migración rural hacia la ciudad de Chone, mediante una metodología teórica, empírica, cualitativa y documental, que permite el análisis de cuatro factores, el social, económico, político y cultural, para aquello se analiza su incidencia en los sectores antes mencionados, de esta manera se pudo conocer que tanto incide la migración rural en el desarrollo sostenible del cantón Chone, lo que nos evidenciará si es favorable o no para el crecimiento económico y además brinda información valiosa para la planificación urbanística y económica del cantón; además permite identificar de qué parroquias rurales se produce la mayor migración, cuáles son sus causas y cuál es el panorama resultante de los sitios de los cuales se emigra.

\section{Materiales y Métodos}

La presente investigación, se realizó en función de un enfoque cualitativo mediante una revisión bibliográfica (informes desarrollados por la CEPAL, INEC, entre otros), que permiten conocer el impacto de la migración existente en el cantón Chone, provincia de Manabí, Ecuador. Con un alcance descriptivo-cuantitativo, en el que se usaron fuentes de información primarias y secundarias, en función de las políticas establecidas por la entidad y la realidad del entorno donde reposa la información verificada, para obtener los datos reales y dar un criterio acertado sobre el impacto provocado por la migración.

\subsection{Métodos}

Descriptivo. - Este método ayudará a determinar los resultados de la investigación y cuáles son las fortalezas y debilidades del sistema.

Revisión bibliográfica. - Mediante esta técnica, se revisarán los informes que contienen los datos reales sobre la situación existente en base a la migración (Estadísticas). 


\section{Investigación Bibliográfica}

\subsection{Migración Global}

Desde la antigüedad, el ser humano ha estado en constante tránsito. Algunas personas se desplazan en busca de trabajo 0 de nuevas oportunidades económicas, para reunirse con sus familiares o para estudiar. Otros se van para escapar de conflictos, persecuciones, del terrorismo o de violaciones o abusos de los derechos humanos. Algunos lo hacen debido a efectos adversos del cambio climático, desastres naturales $u$ otros factores ambientales (Naciones Unidas, 2020).

Los movimientos de población tanto al interior como por fuera de un país, constituyen una de las cuestiones que más atención ha recibido de los estudiosos de los organismos mundiales. Sus causas e impactos, suponen fecundos campos de indagación que contribuyen al saber acumulado de distintas disciplinas. Micolta en el 2005 señaló que existen importantes carencias en el desarrollo teórico del área, que dificultan su comprensión, como consecuencia a su vez, de otros factores como la ambigüedad conceptual del fenómeno, la dificultad de su medición y su carácter multifacético e interdisciplinar.

Como la mayor parte de los temas de moda, la globalización es un término que casi todo profesional de cualquier disciplina utiliza, y para el que no existe una conceptualización claramente definida. En gran medida, se debe a que no hay una definición de globalización que comprenda todas sus perspectivas. Un acercamiento inicial al concepto es, precisamente, su multidimensionalidad. Muñoz en el (2002) planteó que se pueden establecer, entre otras, las siguientes ópticas:

1. La sociocultural. Está vinculada a la generalización internacional de ciertos valores y pautas culturales, cuyo origen se puede encontrar en el mundo occidental a partir de las reformas sociales e innovaciones productivas de la revolución industrial: las concepciones de democracia e igualdad de género, y un consumo abundante.

2. La política. Relacionada con la extensión, bajo la influencia de Estados Unidos, que recomienda la aplicación de políticas nacionales de corte liberalizador, bajo los principios 
del denominado Consenso de Washington, lo que abre las puertas a una mayor vinculación e interdependencia de las diferentes economías.

3. La económica. Se define a través de la supresión de trabas a la circulación internacional de mercancías y de los factores productivos (capital y personas), con el consiguiente aumento de dichos flujos. Es precisamente en esta última percepción en que se centra la atención de este artículo, cuyo objetivo consiste en establecer la forma en que la globalización ha afectado y acelerado los movimientos migratorios.

En contra de lo que frecuentemente se piensa, la explicación de la extraordinaria importancia que se atribuye a la migración en nuestros días no debe buscarse en la magnitud de los flujos. Conviene adelantar que si medir las migraciones, esto es, contar el número de los migrantes, es siempre tarea ardua, tanto por limitaciones estadísticas como por la complejidad conceptual del fenómeno y lo borroso de sus contornos, hacerlo para el conjunto del planeta es tarea condenada a la imprecisión (Arango, 2007).

Los procesos migratorios representan uno de los acontecimientos sociales más importantes de nuestro tiempo, paulatinamente se viene posicionando como un fenómeno de creciente impacto mundial.

El Centro Global de Análisis de Datos de Migración de la OIM es el encargado del Portal Global de Datos Migratorios, que se creó para garantizar que se presenten datos precisos sobre la migración. Se trata de una base de datos centralizada con acceso a estadísticas pertinentes y completas y con información fiable sobre datos de migración a nivel mundial. El sitio presenta datos de migración de diversas fuentes y está diseñado para ayudar a los encargados de formular políticas, los funcionarios nacionales de estadística, los periodistas y al público en general, a navegar por el panorama cada vez más complejo de los datos sobre migración.

En 2017, el número de migrantes internacionales (personas que residen en un país distinto al de su país de nacimiento) alcanzó los 258 
millones en todo el mundo, frente a los 244 millones de 2015. Las mujeres migrantes constituyeron el $48 \%$ de estos. Asimismo, se estima que hay 36,1 millones de niños migrantes, 4,4 millones de estudiantes internacionales y 150,3 millones de trabajadores migrantes. Aproximadamente, Asia acoge el $31 \%$ de la población de migrantes internacionales, Europa el 30\%, las Américas acogen el $26 \%$, África el 10\% y Oceanía, el 3\% (OIM, 2019)

Según las Naciones Unidas en 2019, el número de migrantes alcanzó la cifra de 272 millones, 51 millones más que en 2010. Los migrantes internacionales comprenden un $3,5 \%$ de la población mundial, cifra que continúa en tendencia ascendente comparándola con el $2,8 \%$ de 2000 y el $2,3 \%$ de 1980 .

En la actualidad, una gran cantidad (258 millones) de personas vive en un país distinto de aquel donde nacieron, de las cuales la mayor parte son migrantes trabajadores (150,3 millones) y mujeres $(124,8$ millones), (véase en la figura 1).

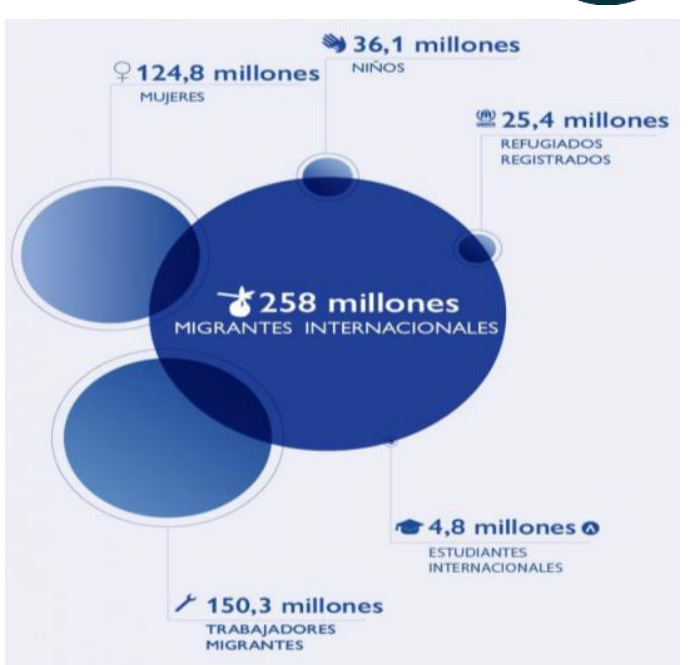

Figura 1. Población de migrantes

\subsection{Migración Latinoamérica}

Dentro de América Latina, la migración intrarregional obedeció a importantes diferenciales entre los niveles de ingreso per cápita de los países, en especial de los limítrofes. Por otra parte, los países latinoamericanos, encabezados por México, se convirtieron en la principal región de origen de los emigrantes que parten hacia los Estados Unidos, tendencia que se acentuó en los decenios de 1980 y 1990 e inicios del siglo XXI.

Según Solimano (2003) las dos fases de globalización de fines del siglo XIX y de fines del siglo XX, así como la desglobalización del período 1913-1945, fueron acontecimientos económicos importantes que afectaron de modo significativo las 
corrientes migratorias a nivel mundial y particularmente a nivel latinoamericano. Se estima que durante estos años, aproximadamente 60 millones de personas abandonaron una Europa con escasos recursos naturales y con exceso de mano de obra, para dirigirse a países del Nuevo Mundo con recursos naturales abundantes y escasez de mano de obra, como Argentina, Australia, Brasil, Canadá, Estados Unidos y Nueva Zelanda. Los migrantes provenían tanto de Inglaterra, Alemania y Francia como de la Europa "periférica" de esa época (los países escandinavos, España, Italia y Portugal, Polonia, Rusia, Rumania y los antiguos países del Imperio Austrohúngaro y del Imperio Otomano). Argentina fue el principal país de destino de los migrantes europeos a América Latina; allí llegaron cerca de siete millones de ellos, de los cuales unos cuatro millones regresaron a su país de origen. Uruguay, Cuba, México y Chile también recibieron un número considerable de migrantes en ese período.

En América Latina, durante la primera fase, Argentina fue el más importante receptor de migrantes europeos. Cerca de siete millones de europeos llegaron al país en ese período, en respuesta a las atractivas oportunidades económicas de la bella época argentina de fines del siglo XIX e inicios del siglo XX. En cambio, en las últimas décadas del siglo $\mathrm{XX}$, Argentina se transformó en país de emigración neta al resto del mundo, particularmente de personas de alto nivel educativo.

En la primera mitad del siglo $\mathrm{XX}$, las corrientes migratorias hacia América Latina provenientes de Europa coexistieron con la emigración desde varias naciones latinoamericanas hacia los Estados Unidos, Canadá y otros países desarrollados. La migración mundial a los Estados Unidos pasó de un millón de personas en la década de 1940, y dos millones y medio en la de 1950, a casi siete millones y medio, en promedio, en los decenios de 1980 y 1990. Vale la pena destacar que mientras los inmigrantes que llegaron a los Estados Unidos en el siglo XIX eran en su gran mayoría europeos (alrededor de $88 \%$ del total de inmigrantes entre 1820 y 1920), el porcentaje de ellos disminuyó a 14\% en el período 1971-1998. En este 
período, la principal región de origen de la migración hacia los Estados Unidos fue América Latina, con un $46 \%$ de la inmigración total, seguida por Asia, con un 34\%. A nivel de países, durante un largo período de 179 años, entre 1820 y 1998, los principales países de origen de migrantes a los Estados Unidos fueron México, Cuba y República Dominicana en América Latina, Filipinas, China, Corea e India en Asia, y Alemania, Italia, Reino Unido e Irlanda en Europa.

Las corrientes migratorias hacia Argentina, el país de la región que más inmigrantes ha recibido, se reanudaron tras el fin de la segunda guerra mundial, a mediados del decenio de 1940, y se prolongaron hasta la segunda mitad de la década de 1950, cuando en Europa se inició una nueva etapa de expansión económica. En contraste, la economía argentina creció a ritmos modestos en la década de 1950, disminuyendo las oportunidades tanto para los inmigrantes como para los nacionales. En 1950, el ingreso per cápita de Argentina, Uruguay y Venezuela seguía siendo superior al de Italia, España y otros países de la Europa periférica, pero la diferencia se reducía cada vez más, y alrededor de 1970 esta relación se había invertido para Argentina y Venezuela. Como se verá en este estudio al analizar con mayor detenimiento el caso argentino, en la década de 1970 los principales incentivos económicos para migrar de Europa hacia Argentina prácticamente habían desaparecido. La migración en sentido contrario, de Argentina hacia España e Italia, marcó la pauta desde entonces (Solimano, 2003).

Es posible distinguir dos momentos en la migración latinoamericana contemporánea hacia España. El primero, de carácter más restringido, se sitúa en el contexto dictatorial que caracterizó a los países del Cono Sur, período en que ciudadanos chilenos, argentinos, uruguayos y brasileños, llegaron como refugiados o exilados políticos a diversos países europeos. Se trata principalmente de una migración calificada formada por universitarios y profesionales. La vuelta a la democracia llevó a que una parte de aquellos regresara a sus países de origen; pero otro grupo decidió quedarse y asumir la nacionalidad del país europeo receptor. Progresivamente, el 
colectivo latinoamericano en Europa se amplió a estudiantes de postgrados, y a emigrantes económicos de clase media en proceso de empobrecimiento, como parte de escenarios de crisis económica y aplicación de programas de ajuste estructural. La migración de dominicanos (Romero, 2003) y peruanos (Merino, 2000) desde mediados de 1980 va preceder la llegada masiva de otras nacionalidades como la colombiana y la ecuatoriana a fines de los años noventa. La exigencia de visado de entrada de España a ciertas nacionalidades, en 1992 para peruanos, en 1993 para dominicanos, va a diversificar los aeropuertos europeos de ingreso a España como destino migratorio privilegiado para las comunidades mencionadas. Diversificación que abrirá las compuertas a la gran heterogeneidad social y cultural que caracteriza el tercer momento, situado entre fines de los años 1990 y 2008, en el que se multiplican las migraciones de diversos países de América del sur hacia España, dando paso a la constitución de un nuevo sistema migratorio Sudamérica-España (OIM, 2011). En el 2001, tres nacionalidades
(Ecuador, Colombia y Argentina) representan casi el $70 \%$ de los sudamericanos: luego los flujos migratorios van a masificarse $y$ diversificarse fuertemente hasta inicios de la crisis recesiva española en el 2008.

La globalización de las migraciones latinoamericanas a inicios del siglo XXI multiplica las rutas en ultramar: además de Estados Unidos -destino más importante- y Asia, se agregan países de Europa del Sur, dinamizando la movilidad intrarregional, y la migración transfronteriza (Martínez, 2012). Los flujos latinoamericanos se diversifican en sus orígenes, destinos, modalidades y perfiles (Yépez \& Herrera, 2007). Si bien el contexto de crisis y de reproducción social de inicios del siglo XXI en América latina enmarcan el fuerte componente laboral de los proyectos migratorios, no deben dejarse de lado problemas ligados a la violencia (política y de género). En diciembre del año 2004 la población latinoamericana oscilaba entre 600 mil y un millón cien mil de migrantes, de estos una gran parte, alrededor de $500 \mathrm{mil}$ en España, aproximadamente 200 mil residentes 
legales son registrados en Italia, y cerca de cien mil, principalmente brasileños en Portugal. En Italia, como lo señalan Queirolo \& Ambrosini (2007), la migración latinoamericana se concentra en Roma, Milán y Génova, laborando principalmente en los servicios asistenciales y domésticos, construcción, limpieza, pequeños transportes y servicios de buses. Una característica importante del colectivo latino es su capacidad para la construcción de redes familiares que facilitan la acogida de nuevos inmigrantes. Además de la importancia de las redes familiares, otro elemento importante es su alto componente femenino, la concentración territorial de los asentamientos, los altos niveles de irregularidad y la concentración laboral en ciertos nichos de trabajo, como to ha analizado Lagomarsino (2006) para los migrantes ecuatorianos en Italia y en Génova específicamente. Entre 1998 y 2009 , el número de migrantes sudamericanos en España se multiplicó por diez, y la población latinoamericana se tornó, con velocidad, en el primer colectivo inmigrante, desplazando a la marroquí. En Italia la presencia latinoamericana fue mucho menor, concentrándose en ciertas regiones como Lombardía y en ciudades como Milán y Bérgamo.

\subsection{Migración en Ecuador}

El cambio de siglo trajo consigo una nueva realidad migratoria al Ecuador. De ser un país de emisión moderada de emigrantes a Estados Unidos, se convirtió en el primer país de la Región Andina de emigración hacia Europa y Estados Unidos. Además, este éxodo se combinó con el crecimiento exponencial de inmigración transfronteriza y con la llegada de un importante número de migrantes en calidad de refugiados. Las transformaciones acaecidas en el país por este nuevo rol de emisor y receptor de flujos migratorios han configurado un nuevo escenario (INEC, 2008).

Según MITRAMISS (2019) desde fines de los años noventa se destaca la llegada masiva de ecuatorianos a España, migración que tiene su momento más intenso entre los años 2000 y 2004, cuando los migrantes procedentes de todo el país y de diferentes sectores sociales, dejaron masivamente el Ecuador, en un contexto de aguda crisis económica y financiera. Se trata del colectivo 
latinoamericano más numeroso. En el año 2013, se encontraban registrados como residentes extranjeros en España 262.223 ecuatorianos. Entre 2002 y 2012 este colectivo representó el $27 \%$ de todas las nacionalizaciones concedidas a extranjeros residentes durante el período señalado. Si se adiciona el número de ecuatorianos nacionalizados y aquellos inscritos como residentes extranjeros estaríamos hablando de más de 470.000 ciudadanos de ese país en el territorio español.

Los registros de la Dirección Nacional de Migración de la Policía Nacional permiten tener un panorama general de cuántas personas han emigrado a través de los saldos entre el número de ecuatorianos que han salido al exterior y los que han ingresado.

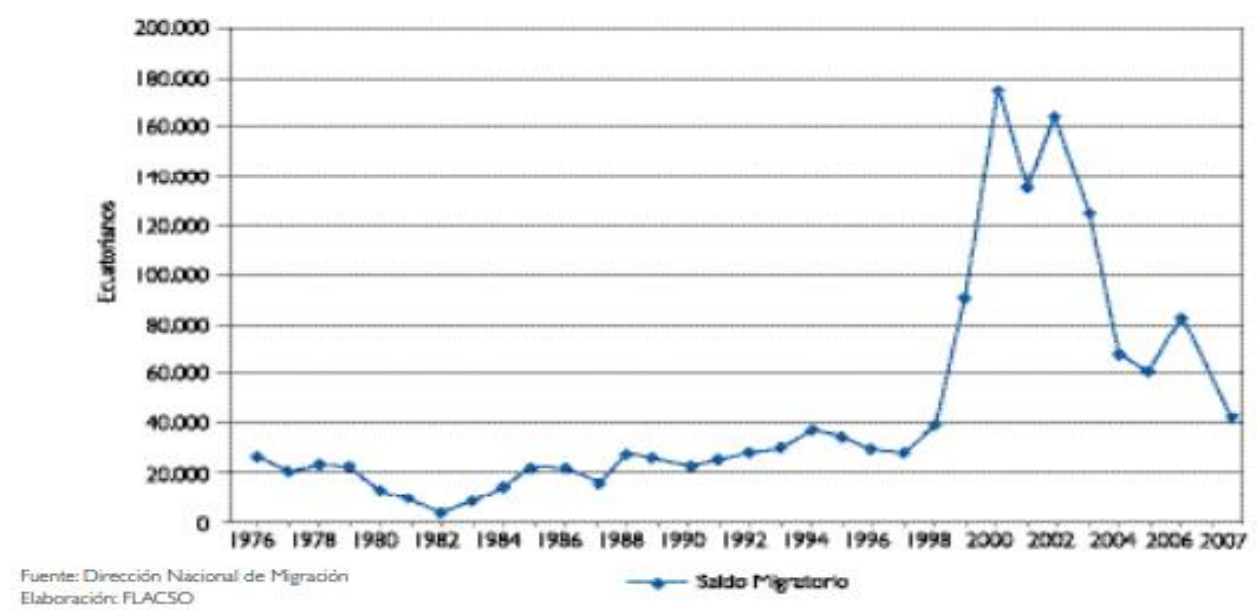

Figura 2. Saldo de migrantes

En la figura 2 se puede apreciar que la migración en Ecuador se mantenía en una línea promedio en el saldo de migración de 20.000 migrantes aproximadamente, esto hasta el año 1997, en el cual el saldo migratorio se incrementó hasta alcanzar un punto máximo de 175.922 migrantes en el año 2000 , de ahí se presentó una tendencia hacia la disminución; esto debido a la imposición de la visa a España y a los países del Tratado Schengen, Ilegando en el 2007 a tener un saldo migratorio de 42.399 migrantes.

Hay que señalar que en estos registros no constan las personas que salen por canales irregulares. 
Varios estudios de caso han mostrado que la vía marítima se ha convertido en un canal cada vez más frecuente para la emigración ecuatoriana a Estados Unidos (Jokisch \& Kyle, 2005).

\subsection{Migración rural}

La migración puede ser un motor de crecimiento económico e innovación, y puede contribuir de manera significativa al desarrollo sostenible y la reducción de las desigualdades tanto dentro como entre los países. La FAO (2019) reconoce que la migración forma parte de la evolución de las sociedades y del proceso de desarrollo y transformación económico, social y humano. FAO se ha centrado en la migración rural, desde, hacia y entre zonas rurales, independiente de la duración, dirección o causas del movimiento migratorio. La FAO se enfoca tanto en las migraciones internacionales como internas, reconociendo que la migración interna supera ampliamente la migración internacional a medida que los países van transitando de sociedades predominantemente rurales a sociedades cada vez más urbanas. Las personas que se desplazan internamente también son más proclives a trasladarse al extranjero que aquellas que jamás lo han hecho.

\subsubsection{Migración rural-urbana en el cantón Chone, Ecuador}

Chone es el tercer cantón de Manabí en población y en economía, tiene una superficie de $3.570 \mathrm{~km}^{2}$. Limita al norte con el cantón Pedernales y la provincia de Esmeraldas; al sur con los cantones Pichincha, Bolívar, Tosagua; al este con la provincia de Esmeraldas y los cantones EI Carmen, Flavio Alfaro; y al oeste con los cantones San Vicente, Sucre (Parroquia San Isidro), Jama y Pedernales. Cuenta con 7 parroquias rurales: Boyacá Convento, Canuto, Eloy Alfaro, Ricaurte, San Antonio y Chibunga (Gobierno Municipal del Cantón Chone, 2008).

En el cantón Chone según el Sistema Nacional de Información (SNI, 2013) la mayor actividad comercial está representada por el comercio con 55,18\%. Posteriormente están los servicios con $36,14 \%$, de los cuales la mayor parte se dedican al servicio de alimentos y bebidas. Finalmente, en tercer lugar, se encuentra la Manufactura con $8,68 \%$ (figura 3 ). 


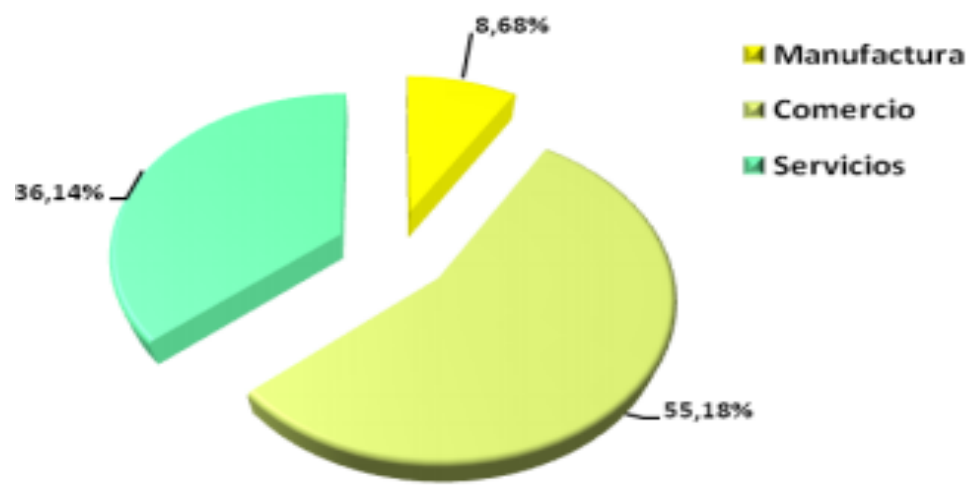

Figura 3. Sectores productivos del cantón Chone

Según los datos obtenidos por el Instituto Nacional de Estadísticas y Censos (INEC) en el último censo (2010), el cantón Chone presenta una población total de 126.491 habitantes en las áreas urbanas y rurales. En el área urbana la población es de 52.810 habitantes, de los cuales 25.158 son hombres y 27.652 son mujeres; en cuanto al área rural, la población es de 73.681 habitantes, de los cuales 38.125 son hombres y 35.556 son mujeres, según lo expuesto en la figura 4.

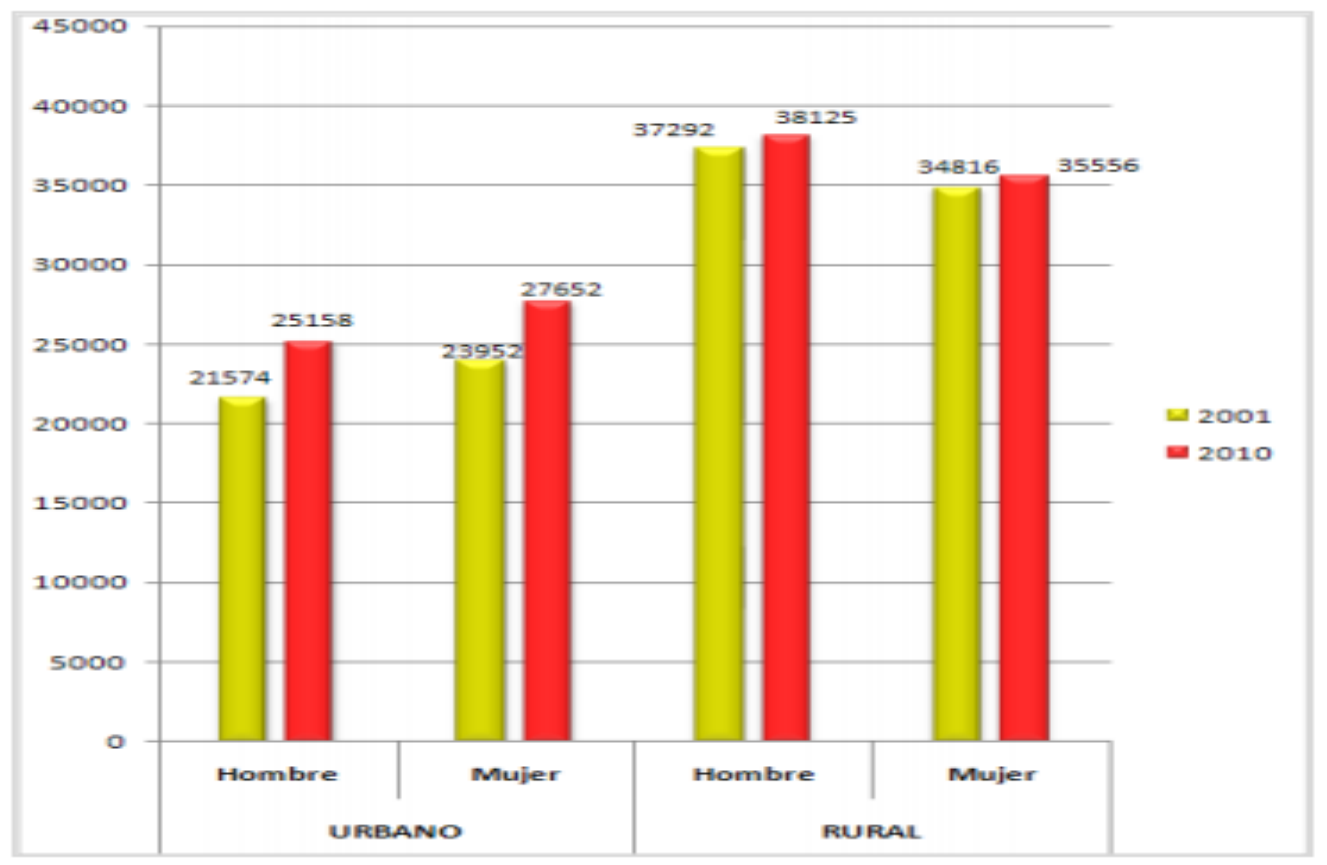

Figura 4. Población del área rural y urbana por sexo 
Realizando un análisis comparativo entre los datos del censo 2001 y los datos del censo 2010, se aprecia un incremento poblacional, tanto en el área urbana como rural.
Consecuentemente, en el área rural existe un aumento porcentual del $2,13 \%$, mientras que en el área urbana existió un aumento del $13,79 \%$ (Tabla 1).

Tabla 1. Variación de la población urbana y rural del cantón Chone

\begin{tabular}{ccc|cc}
\hline \multirow{2}{*}{ Sexo } & \multicolumn{4}{c}{ 2001-2010 } \\
\cline { 2 - 5 } & \multicolumn{2}{c}{ Variación Rural } & \multicolumn{2}{c}{ Variación Urbana } \\
\cline { 2 - 5 } & Absoluto & Relativo (\%) & Absoluto & Relativo (\%) \\
\hline Hombres & 830 & 2,18 & 3584 & 14,25 \\
\hline Mujeres & 744 & 2,08 & 3700 & 13,38 \\
\hline Total & 1574 & 2,13 & 7284 & 13,79 \\
\hline
\end{tabular}

Según el SNI (2013) esta situación puede darse por diversos factores; en el área urbana prevalece un fenómeno migratorio y de colonización, debido a que el casco urbano representa un sector en crecimiento al cual muchos pobladores de distintas provincias y de parroquias del mismo cantón buscan para desarrollar sus actividades diarias. Mientras que en el sector rural que tiene un menor porcentaje de variación, predomina un crecimiento vegetativo y en menor medida el impacto de la migración y colonización.
El analfabetismo además de limitar el pleno desarrollo de las personas y su participación en la sociedad, tiene repercusiones durante todo su ciclo vital, afectando el entorno familiar, restringiendo el acceso a los beneficios del desarrollo $y$ obstaculizando el goce de otros derechos humanos (CEPAL, 2010). Según el último censo realizado en el 2010 por el INEC, la tasa de analfabetismo a nivel cantonal fue de $11,04 \%$; el cual es un dato menor al registrado en el año 2001, donde se presentaba una tasa de $13,32 \%$. Para el año 2010 la parroquia con un mayor índice de analfabetismo es Chibunga con un $20,01 \%$, mientras 
que la cabecera cantonal Chone, es la parroquia con menos analfabetismo, como se observa en la figura 5 .

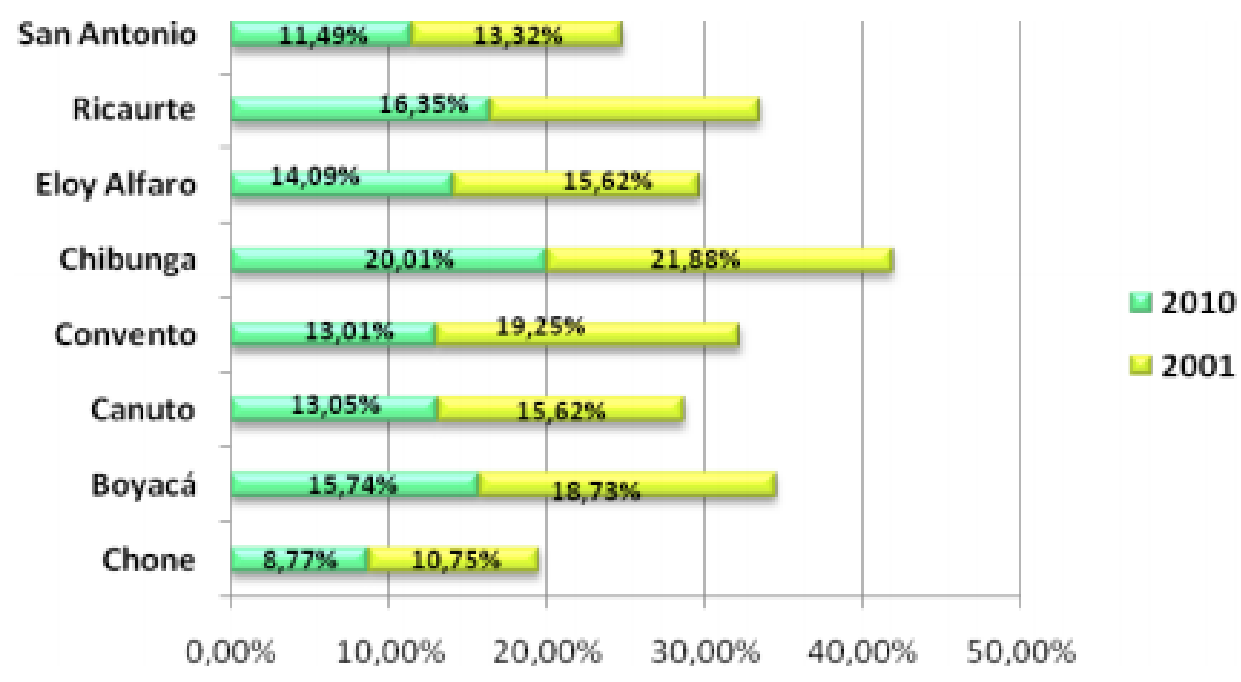

Figura 5. Tasa de analfabetismo del cantón Chone

Las consecuencias del analfabetismo son tanto físicas como psicológicas y acompañan al individuo durante toda su vida; en los niños y las niñas, el analfabetismo se expresa en el adecuado proceso de desarrollo de sus células y su posterior capacidad del desarrollo del aprendizaje y en la socialización. Los padres analfabetos tienen serias limitaciones para brindar experiencias de aprendizaje de comunicación, lectura y escritura a sus hijos, limitando el desarrollo físico y social de los niños. Como los padres analfabetos tienen menos expectativas y aspiraciones educacionales para sí mismos y para sus hijos es frecuente que se privilegie el trabajo antes que la educación por creer que es más beneficioso.

El acceso a servicios básicos es el factor que ha determinado la reproducción de algunas sociedades. El surgimiento de los servicios básicos que busca satisfacer necesidades sociales básicas, se ve atado al desarrollo de lo social, de la convivencia del ser humano en sociedad, más allá de las necesidades inmediatas y puntuales de los individuos. Garantizar el acceso a bienes y servicios básicos a través de diversos modos de 
prestación y provisión, atendiendo a su aprovechamiento social, es un mecanismo de asegurar la reproducción de las condiciones básicas de la vida humana, respetando las formas $y$ construcciones histórico-culturales, y respetando los límites físicos de la naturaleza (SNI, 2013).

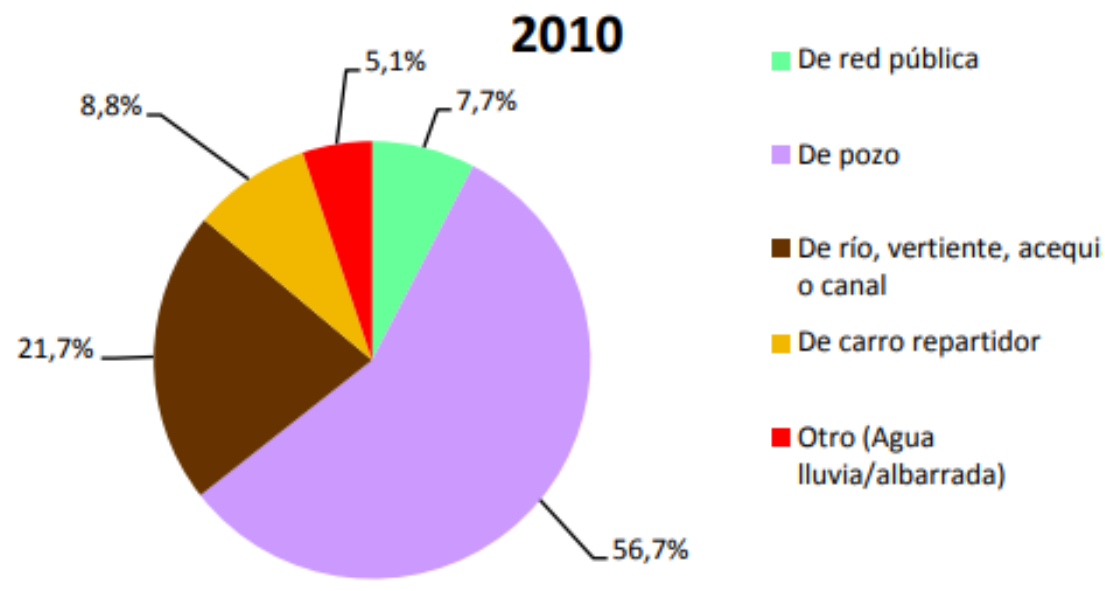

Figura 6. Disponibilidad al servicio de abastecimiento de agua en el área rural

Se considera que el abastecimiento de agua por medio de la red pública es el sistema que presta mejor atención. En la zona rural de Chone solo el $7,7 \%$ de la población se abastece de agua mediante la red pública, mientras que un $56,7 \%$ utiliza agua de pozo, en tanto que el $21,7 \%$ recoge agua del río, vertiente, acequia o canal, y un $8,8 \%$ de carro repartidor. Estos datos son preocupantes, ya que los medios principales de abastecimiento de agua en Chone son poco salubres, los pozos deben tener un tratamiento adecuado caso contrario el agua puede contaminarse con bacterias coliformes causantes de enfermedades como la parasitosis o infecciones intestinales.

Esta situación alarma debido a que la mayor parte del cantón no cuenta con todos los servicios básicos indispensables para tener una buena calidad de vida. Los servicios se han concentrado en una parte de la cabecera cantonal y en la parroquia Canuto, mientras que los demás sectores no cuentan con todas las facilidades (SNI, 2013).

Tomando como punto de partida la información generada por 
instituciones públicas como el INEC en los censos 2001 y 2010. Las parroquias con mayor disminución de la tasa de pobreza por Necesidades Básicas Insatisfechas (NBI) son Chone y Canuto. Mientras que en Chibunga este indicador aumentó en un 1,4\%. Es importante mencionar que la tasa de pobreza por NBI en el cantón es alta, debido a que todas las parroquias presentan una tasa mayor al $60 \%$ y la variación existente cantonal y parroquialmente es mínima, como se observa en la figura 7. Esto manifiesta que la mayor parte de la población todavía no tiene buenas condiciones de vida.

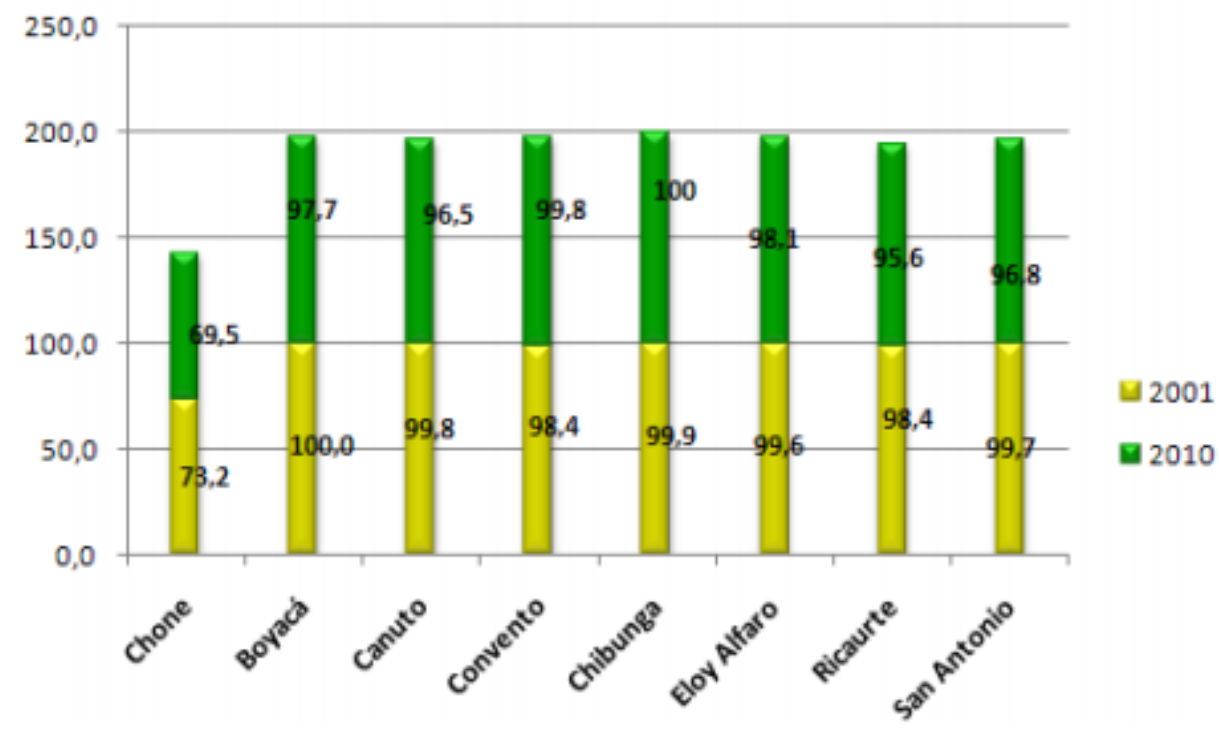

Figura 7. Porcentaje de pobreza en las parroquias del cantón Chone

\section{Conclusiones}

La presente investigación, realizada mediante una extensa revisión bibliográfica, nos permite conocer el impacto generado por la migración rural-urbana en el cantón Chone de la provincia de Manabí, Ecuador.

Las actividades productivas de Chone están relacionadas principalmente con la agricultura y la ganadería. Sin embargo, un gran problema, principalmente para las personas que se ubican en la zona baja del cantón, son las inundaciones en invierno que arrasan con los sembríos y la inexistente diversificación de actividades que complemente la dinámica productiva de Chone. 
Este fenómeno de la migración rural urbana se da ya que un gran porcentaje de la población se dedica a la agricultura, y la cercanía a la urbe es un punto clave para la venta de sus productos. Por otro lado, la menor concentración de población se da en los sectores de Chibunga y Convento, debido al mal estado de las vías, a las inundaciones del sector y la poca accesibilidad que tienen para desarrollar sus trabajos. Lo que hace que un pequeño porcentaje de la población se asiente en estas zonas.

El porcentaje de analfabetismo en Chone es alto $(11,04 \%)$ y la disminución de este indicador a nivel de parroquias es mínimo, principalmente en las poblaciones que se encuentran más lejanas a la cabecera cantonal. Esto se debe principalmente a que el acceso a los centros de educación no es bueno, al no existir vías que faciliten la movilización de los estudiantes.

En base al censo del 2010 se puede distinguir que la cobertura de los servicios en el cantón Chone es baja, la población que goza casi de todos los servicios es la que se encuentra en el casco urbano, y en las zonas cercanas a las cabeceras parroquiales.

Existen buenas iniciativas microempresariales en el cantón que han podido fluir gracias a la ayuda de las juntas parroquiales y a la autogestión. Por lo general estas iniciativas están relacionadas con la agricultura y ganadería.

El porcentaje de pobreza por necesidades básicas insatisfechas es muy alto, lo cual indica que un gran porcentaje de la población todavía no cuenta con un buen estilo de vida. La única parroquia rural que cuenta con el servicio de agua potable y alcantarillado es Canuto, por tal razón en la parroquia ha existido un incremento poblacional y la plusvalía en el sector ha aumentado.

Cabe acotar que la mayoría del territorio del cantón Chone se encuentra en zonas bajas y propicias a inundaciones en el invierno, lo cual provoca la pérdida de cultivos y la inaccesibilidad a los centros educativos y de salud. Aunque la cabecera cantonal también es zona inundable, existen mejores procesos para combatir el fenómeno, mientras que en los sectores alejados en invierno la situación es bastante 
complicada. Por tal razón los habitantes prefieren concentrarse en zonas altas, y en lugares cercanos a la urbe.

Por lo tanto, se concluye que la migración interna es un factor que tiene efectos directos en los procesos de urbanización, mismos que se han visto influidos por la mecanización de la agricultura, la concentración y acumulación de la propiedad rural y el escaso dinamismo del sector agrícola tradicional. La mayoría de la población se concentra en zonas donde existe disponibilidad de servicios básicos, infraestructura educación y salud; de preferencia con cercanía o con buena accesibilidad. De tal manera que, la concentración de la población en el cantón Chone se encuentra en la parte centro-sur, cerca de la cabecera parroquial Chone, de San Antonio y Canuto.

\section{Bibliografía}

Arango, J. (2007). Las migraciones internacionales en un mundo globalizado. Vanguardia Dossier, 22.

CEPAL. (2010). Comisión Económica para América
Latina y el Caribe. Obtenido de: www.cepal.org: https://repositorio.cepal.org/ bitstream/handle/11362/374 7/S2009862_es.pdf?sequen $\mathrm{ce}=1 \&$ is Allowed $=\mathrm{y}$

CEPAL. (2018). Comisión Económica para América Latina y el Caribe. Obtenido de:

https://www.cepal.org/es/pu blicaciones/43584panorama-la-migracioninternacional-america-sur

Eguiguren, M. M. (2017). Los estudios de la migración en Ecuador: del desarrollo nacional a las movilidades. Íconos. Revista de Ciencias Sociales, (58), 59-81. https://dx.doi.org/10.17141/i conos.58.2017.2497

FAO. (2019). Organización de las Naciones Unidas para la Alimentación y la Agricultura. Obtenido de: http://www.fao.org/3/ca2717 es/ca2717es.pdf

Gobierno Municipal del Cantón Chone. (2008). Obtenido de: https://www.chone.gob.ec/p df/pdyotcantonchone.pdf 
INEC. (2008). Instituto Nacional de Estadísticas y Censos. Ecuador en Cifras. Obtenido de:

https://www.ecuadorencifras .gob.ec/institucional/home/: https://flacsoandes.edu.ec/w eb/imagesFTP/7586.6721.m igracion_ecuador_en_cifras _2008.pdf

INEC. (2010). Instituto Nacional de Estadísticas y Censos. Ecuador en Cifras. Obtenido de:

www.ecuadorencifras.gob.e C: https://www.ecuadorencifras .gob.ec/documentos/webinec/Bibliotecas/Fasciculos_ Censales/Fasc_Cantonales/ Manabi/Fasciculo_Chone.pd f

INEC. (2019). Instituto Nacional de Estadística y Censos. Ecuador en Cifras. Obtenido de:

www.ecuadorencifras.gob.e

C:

https://www.ecuadorencifras .gob.ec/comisionesespeciales-de-estadistica/
Jokisch, B., \& Kyle, D. (2005). Las transformaciones de la migración transnacional del Ecuador, 1993- 2003 en La migración ecuatoriana: transnacionalismo, redes e identidades, editado por Herrera, G.; Torres, A. y Carrillo, M.C. Quito: FLACSO-Plan Migración, Comunicación y Desarrollo.

Lagomarsino, F. (2006). ¿Cuál es la relación entre familia y migración? En G. Herrera et al., 2006. La migración ecuatoriana transnacionalismo, redes e identidades, FLACSO, Ecuador, pp. 335-358.

Martínez, J. (2012). Migración internacional en América Latina y El Caribe. Nuevas tendencias, nuevos enfoques, CEPAL, Santiago.

Merino, A. (2000). La inmigración peruana a España: motivos, momentos y formas de ingreso en los noventa. Comunicación presentada en el II Congreso de la Inmigración en España, 
Universidad Pontificia de Comillas, octubre 2000.

Micolta, A. (2005). Teorías y conceptos asociados al estudio de las migraciones internacionales. Trabajo Social, 59-76.

MITRAMISS. (2019). Ministerio de Trabajo, Migraciones y Seguridad Social. Obtenido de: www.mitramiss.gob.es: http://extranjeros.inclusion.g ob.es/es/estadisticas/operac iones/con-

certificado/index.html

Muñoz-Jumilla, A. (2002). Efectos de la globalización en las migraciones internacionales. Papeles de población, 8(33), 9-45.

http://www.scielo.org.mx/sci elo.php?script=sci_arttext\&p id $=$ S1405-

$74252002000300002 \& \operatorname{lng}=e$ s\&tlng=es.

OIM. (2011). Perfil Migratorio de Uruguay. Organización Internacional para las Migraciones. OIM, Buenos Aires.
ONU. (2020). Organización de las Naciones Unidas. Obtenido de:

https://www.un.org/es/sectio ns/issuesdepth/migration/index.html

Petit, J. M. (2002). Migraciones, vulnerabilidad y políticas públicas. Comisión Económica para América Latina y el Caribe (CEPAL) Organización Internacional para las Migraciones (OIM), 2-20.

Queirolo, L. \& Ambrosini, M. (2007). Lecciones de la inmigración latina a Europa e Italia. En I. Yépez, y G. Herrera, 2007. Nuevas Migraciones latinoamericanas a Europa. Balances y desafíos, OBREAL, FLACSO Ecuador, Quito, pp. 95-112.

Romero, J. (2003). La migración dominicana hacia España, factores, evolución y desarrollo. En Regué européene des Migrations Internationales, 19(1), pp.147-171. 
SNI. (2013). Sistema Nacional de Información. Obtenido de www.sni.gob.ec:

http://app.sni.gob.ec/snilink/sni/PDOT/ZONA4/NIVE L_DEL_PDOT_CANTONAL/ MANABI/CHONE/IEE/MEM ORIAS_TECNICAS/mt_cho ne_socioeconomico.pdf

Solimano, A. (2003). Globalización y migración internacional: la experiencia latinoamericana. Revista de la CEPAL No.80, 55-72.

Villarroya, E. (2014). El impacto social de la movilidad humana, una visión no dicotómica del cambio cultural e individual. Valencia: MÈTODE Science Studies Journal.

Walmsley,

E. (2001).

Transformando los pueblos: La migración Internacional y el Impacto social al nivel comunitario. Centro Andino de Acción Popular CAAP, 3 23.

Yépez, I. \& Herrera, G. (2007). Nuevas Migraciones latinoamericanas a Europa. Balances y desafíos, OBREAL, FLACSOEcuador, Quito. 